\title{
Skeletal Dysplasia (Sclerosing dysplasias - Part I)
}

\author{
Subbarao K \\ Padmasri Awardee Prof. Dr. Kakarla Subbarao, Hyderabad, India
}

\section{Introduction}

Dysplasia is a disturbance in the structure of bone and disturbance in growth intrinsic to bone and / or cartilage. Several terms have been used to describe Skeletal Dysplasia. Skeletal dysplasias constitute a complex group of bone and cartilage disorders. Three main groups have been reported. The first one is thought to be $\mathrm{x}$-linked disorder genetically inherited either as dominant or recessive trait. The second group is spontaneous mutation. Third includes exposure to toxic or infective agent disrupting normal skeletal development.

The term skeletal dysplasia is sometimes used to include conditions which are not actually skeletal dysplasia. According to revised classification of the constitutional disorders of bone these conditions are divided into two broad groups: the osteochondrodysplasias and the dysostoses.

There are more than 450 well documented skeletal dysplasias. Many of the skeletal dysplasias can be diagnosed in utero. This paper deals with post natal skeletal dysplasias, particularly Sclerosing dysplasias.

\section{Dysplasias with increased bone density}

Disturbance in bone structure or Modeling which assumes disturbance in growth intrinsic to bone

Dysostosis is a misnomer indicates malformation of Individual bones singly or in combination. The international skeletal dysplasia society has classified a large heterogeneous group ranging in severity.
Monitoring germ cell Mutations using skeletal dysplasias incidence of dysplasia is 1500 for 9.5 million births (15 per $1,00,000)$

\section{SCLEROSING DYSPLASIAS}

Osteopetrosis

$>$ Pyknodysostosis

$>$ Osteopoikilosis

$>$ Osteopathia striata

$>$ Dysosteosclerosis

$>$ Worth's sclerosteosis

$>$ Van buchem's dysplasia

$>$ Camurati Engelman's dysplasia

$>$ Ribbing's dysplasia

$>$ Pyle's metaphyseal dysplasia

$>$ Melorheosteosis

$>$ Osteoectasia with hyperphosphatasia

$>$ Pachydermoperiosteosis (TouraineSolente-Gole Syndrome)

Evaluation by skeletal survey including long bones thoracic cage, hands, feet, cranium and pelvis is adequate. Sclerosing dysplasias are described according to site of affliction epiphyseal, metaphyseal, diaphyseal and generalized.

Osteopetrosis (Marble Bones): Three forms are reported. The most common form is autosomal dominant. The second common is malignant form which is autosomal recessive. The rare form is associated with tubular acidosis. In all the forms generalized increased in bone density is noted (fig.1). The normal trabeculae are obliterated. With trauma, banana types of fractures are noted in long bones (fig. 2). The normal bone density and the increased density produce 


\begin{tabular}{|l|l|}
\hline Osteochondrodysplasia & Dysostoses \\
\hline $\begin{array}{l}\text { Abnormalities are intrinsic to bone and } \\
\text { cartilage }\end{array}$ & $\begin{array}{l}\text { Occur as a result of abnormalities of } \\
\text { blastogenesis in the first } 6 \text { weeks of fetal life } \\
\text { resulting in defective bone formation. }\end{array}$ \\
\hline $\begin{array}{l}\text { Phenotypes continue to evolve throughout } \\
\text { life i.e. previously apparently unaffected } \\
\text { bones and joints may subsequently } \\
\text { demonstrate abnormality, so the diagnosis } \\
\text { may be made either at birth or later }\end{array}$ & $\begin{array}{l}\text { Phenotype is static throughout life, so } \\
\text { changes in affected bones may progress, but } \\
\text { the malformations do not spread to involve } \\
\text { previously normal bones and joints }\end{array}$ \\
\hline $\begin{array}{l}\text { Multiple bones of the axial and appendicular } \\
\text { skeleton are usually involved }\end{array}$ & $\begin{array}{l}\text { Malformations of individual bones but } \\
\text { several bones in combination may be } \\
\text { affected }\end{array}$ \\
\hline \hline Subdivided into 33 broad groups & $\begin{array}{l}\text { Subdivided into three main groups: group A } \\
\text { with predominantly craniofacial } \\
\text { involvement, group B with predominant } \\
\text { axial involvement, and group C with } \\
\text { predominant involvement of the hands and } \\
\text { feet. }\end{array}$ \\
\hline
\end{tabular}

transverse bands in long bones and flat bones. A bone within a bone pattern is noted particularly in innominate bones, calcaneum and ribs (fig. 3). Modeling deformities of long bones are also noted (fig.4). In spine, sandwich vertebra is common. Changes in skull or variable with increased density at the base(fig.5). In osteopetrosis associated with tubular acidosis rachitic changes are noted.

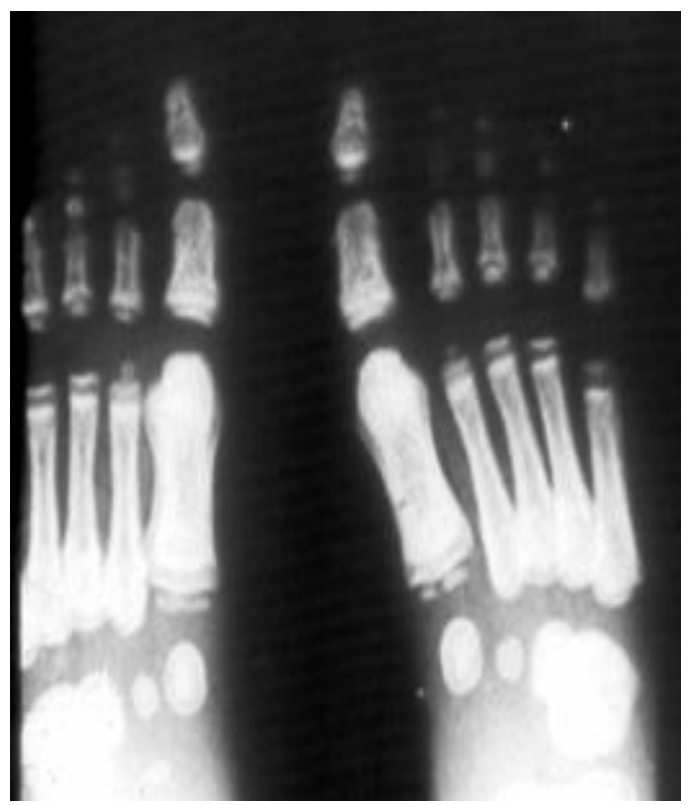

Fig. 1: Osteopetrosis - Generalized bone density in the feet of a child

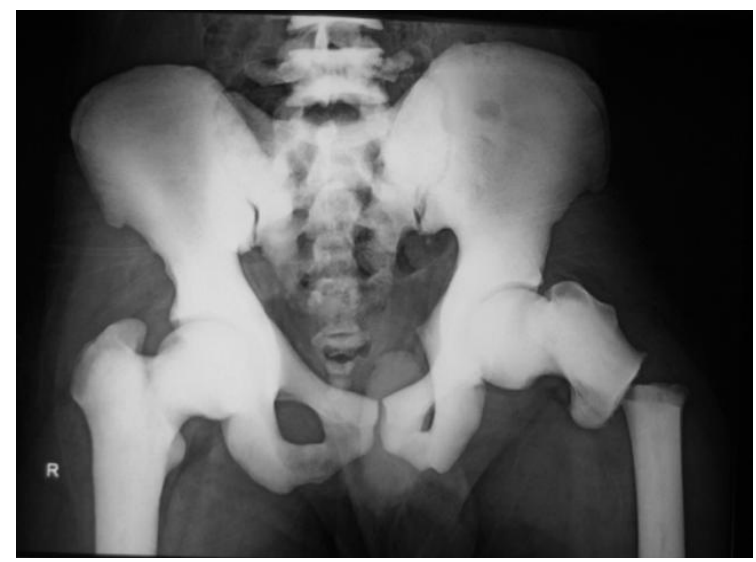

Fig. 2: Osteopetrosis - Osteosclerosis with obliteration of the trabeculae. Note the "banana" type of fracture in the left femur.

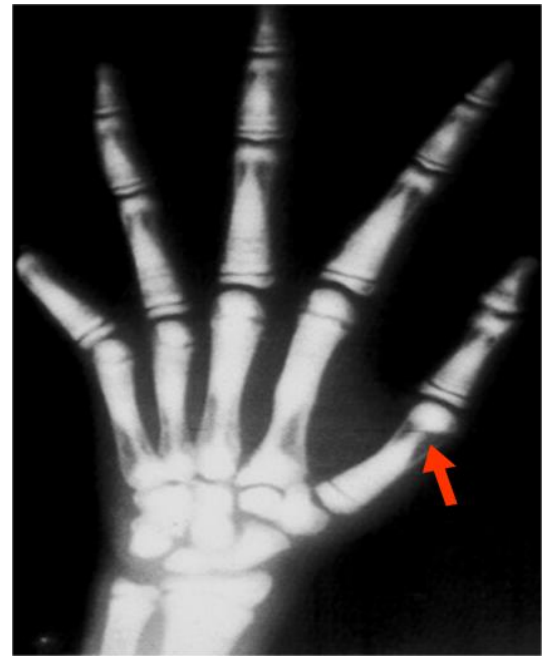

Fig. 3: Osteopetrosis - "Bone in a bone" in the hand 


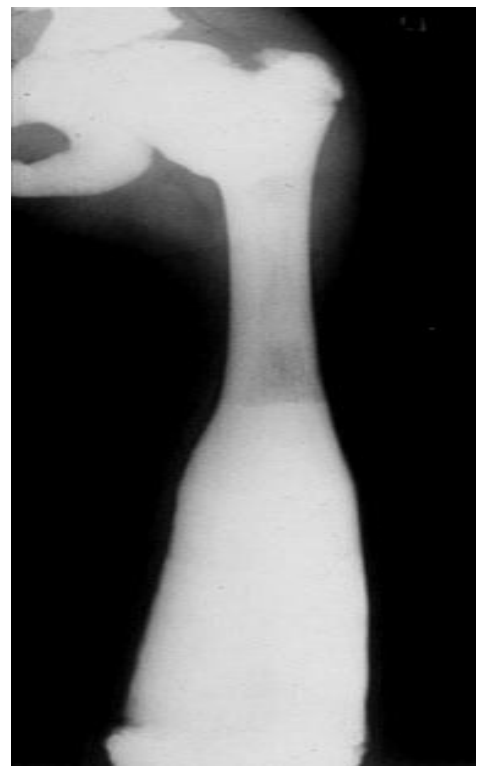

Fig. 4: Osteopetrosis - Modeling deformity simulating Erlenmyer Flask appearance.

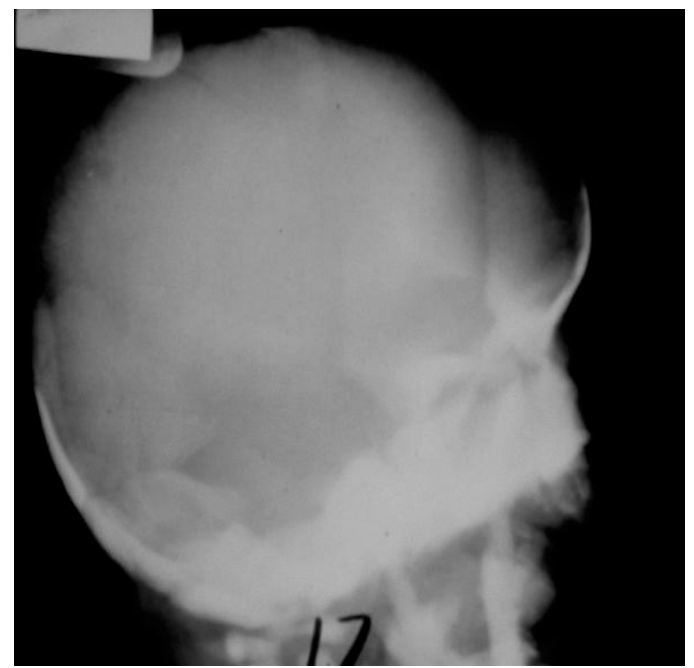

Fig. 5: Osteopetrosis - lateral view of skull. Note the dense bones at the base of the skull.

\section{Pycnodysostosis(Toulouse-Lautrec)- French Artist had similar features}

It is a hybrid between osteopetrosis and Cleidocranial dysostosis. Major sites include skull, mandible, clavicles and spine. All the bones are uniformly sclerotic. However, skull findings include frontal bossing, persistent fontanels, wormian bones an obtuse angle of mandible is noted (fig.6). There is clavicular hypoplasia (fig.7). Acro osteolysis is noted (fig. 8).

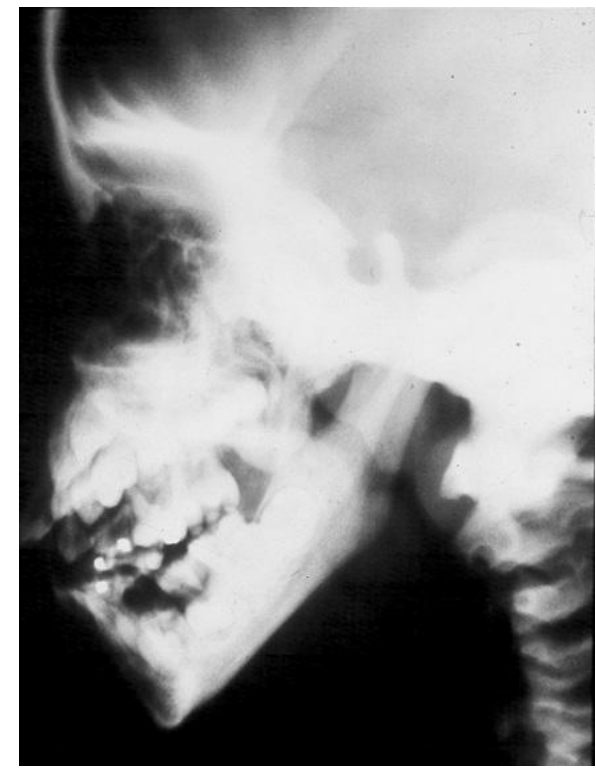

Fig.6: Pycnodysostosis - Note the obtuse angle of the mandible.

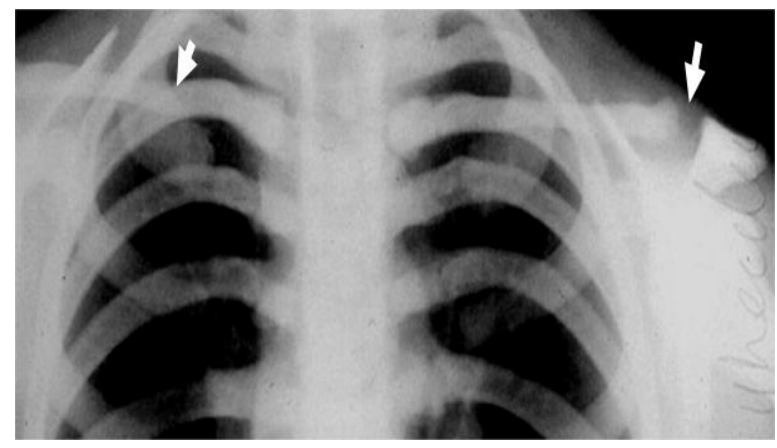

Fig.7: Pycnodysostosis - Note the hypoplasia of the clavicles.

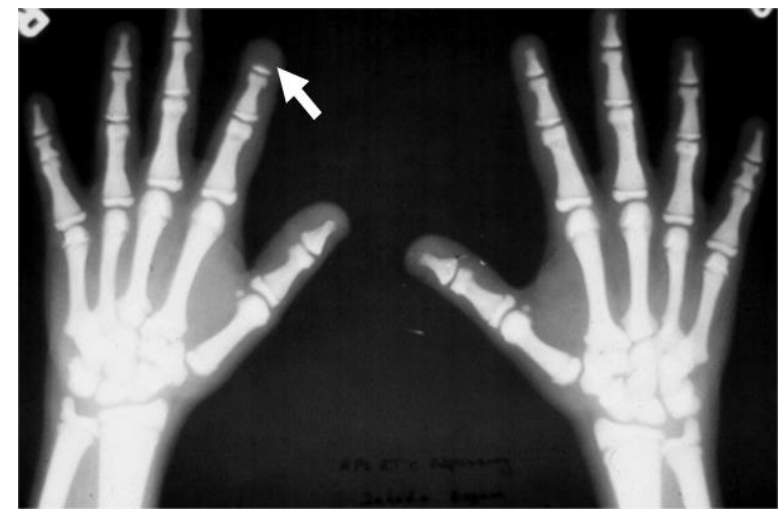

Fig. 8: Pycnodysostosis - Note acro osteolysis

The major differences between osteopetrosis and pycnodysostosis include persistent fontanels and wormian bones in the skull, obtuse angle of mandible, clavicular hypoplasia and acro osteolysis, which are present in pycnodysostosis. 


\section{Osteopoikilosis - Autosomal dominant}

It is relatively uncommon familial disorder and seen at any age. Punctate or even short linear densities of compact bone varying in size from $1-10 \mathrm{~mm}$ are noted. These are common towards long bones particularly articular ends (fig.9).

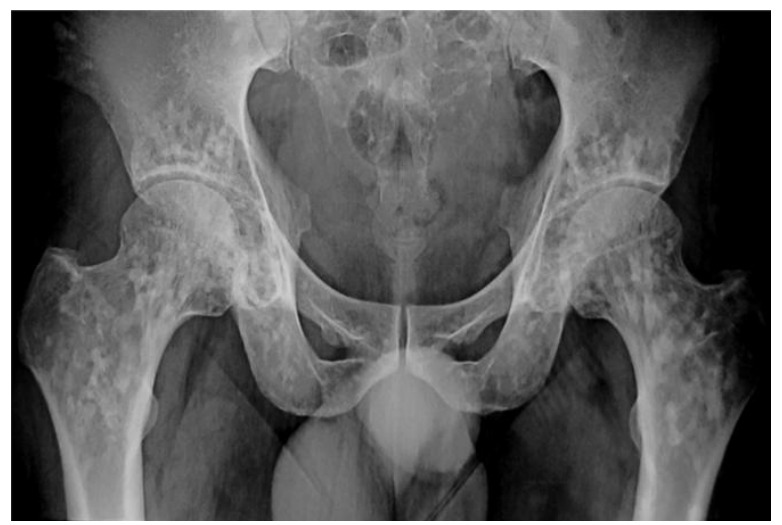

Fig.9:Osteopoikilosis - Note the spotty bones at the juxta articular region of the hip
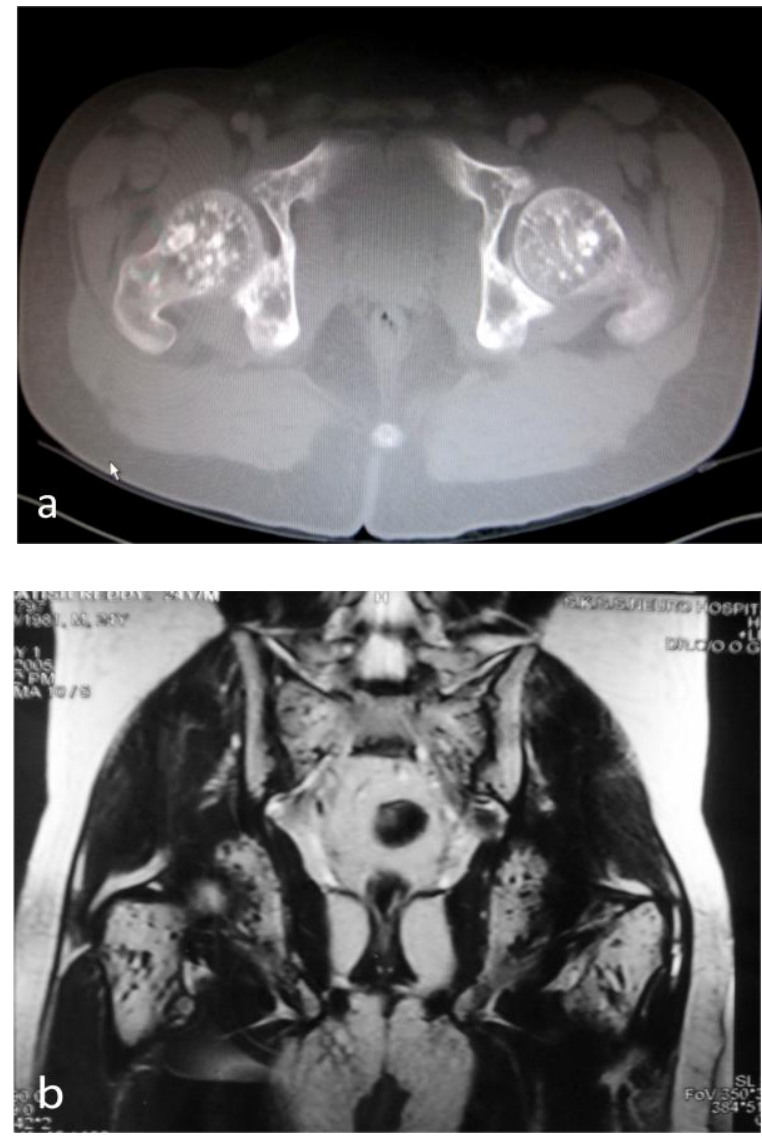

Fig. 10ab: Osteopoikilosis - a. CT, b. MRI (over investigations)
Common in pelvic bones (fig.10ab). Spine, skull and ribs rarely show the findings. Findings are similar to bone islands, which are inclusions of cortical bone in spongiosa.

Patients having both osteopoikilosis and osteosarcoma have been described. Osteosarcoma is related to active osteogenesis. It has been proposed that perhaps the chronic remodeling of osteopoikilosis has resulted in malignant degeneration.

\section{Osteopathia striata}

It is another sclerosing dysplasia affecting the secondary spongiosa, generally detected incidentally. It is characterized by multiple linear densities of varying widths. These are prominent in the ends of long bones within medulary cavities. They may extend into epiphysis (fig.11ab). Linear striations may also occur in other sclerosing dysplasias
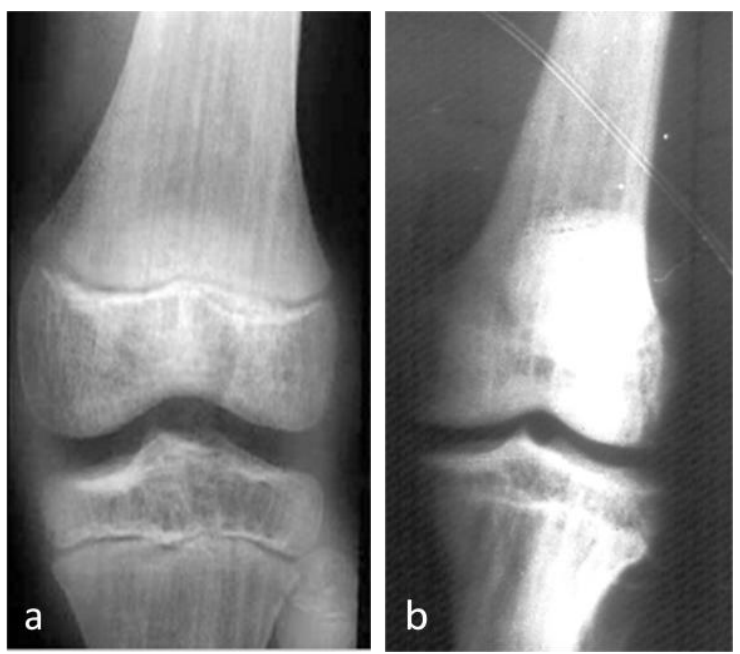

Fig. 11ab: Osteopathia Striata, Knee - a. Child, b. Adult

\section{Dysosteosclerosis}

Radiological findings include progressive marked hyperostosis of the skull and mandible (fig. 12). The vertebral endplates, pedicles and the bones of the pelvis are sclerotic (fig. 13ab). The long bones are enlarged, with cortical hyperostosis. Moderate alteration of the bone contours, 
and lack of normal diaphyseal constriction and pathologic fractures do not occur.

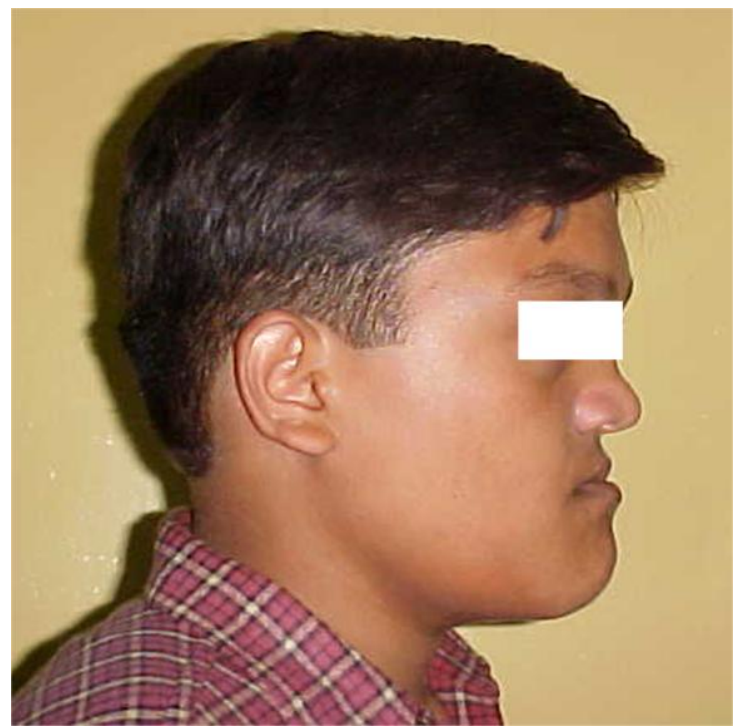

Fig. 12: Dysosteosclerosis - Clinical

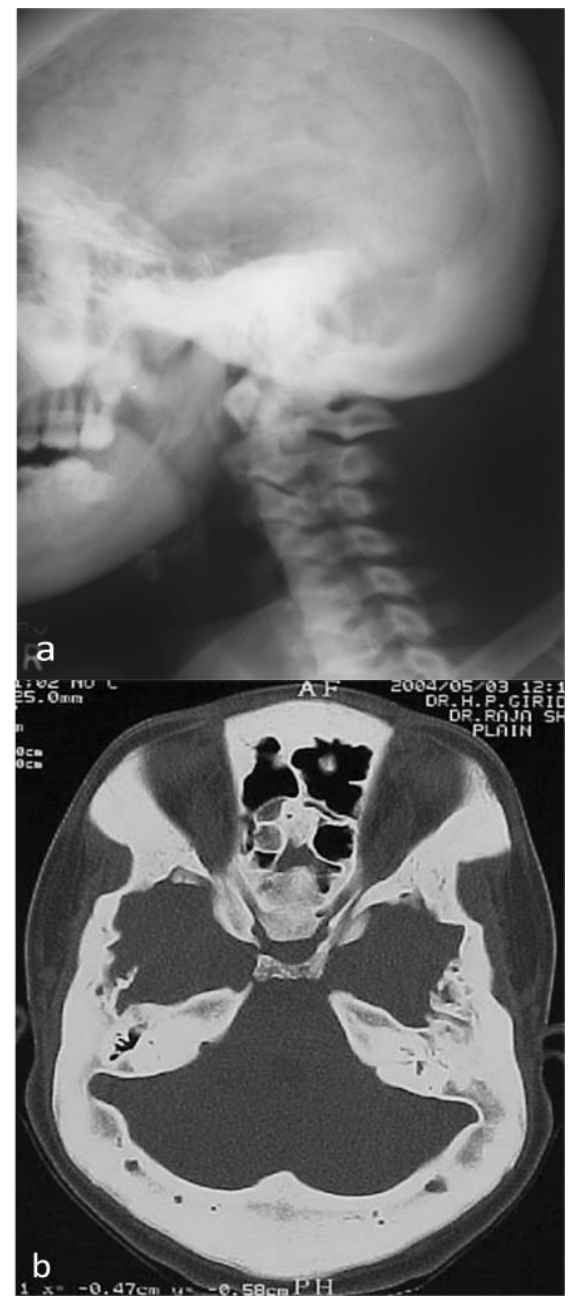

Fig.13ab: Dysosteosclerosis- a. Skull and mandible, b. CT base of skull.

\section{WORTH'S SCLEROSTEOSIS}

It is another variant of dysosteosclerosis. Radiographic findings include endosteal thickening in the cortex of the tubular bones with encroachment on the medullary cavity. Osteosclerosis begins in the base and subsequently involves the facial bones, especially the mandible. The latter bone lacks the normal antegonial notch, and the mandibular canal may be prominent

\section{Van Buchem's Type of Endosteal} Hyperostosis - Hyperostosis corticalis generalisata. It is a rare hereditary autosomal recessive disorder. Calvaria, mandible, clavicles, innominate bones and extremity bones are involved (fig.14). Specific abnormalities include periosteal excrescences in the tubular bones, osteosclerotic and enlarged ribs, and clavicles, and increased radiodensity of the spine, particularly prominent in the spinous processes.

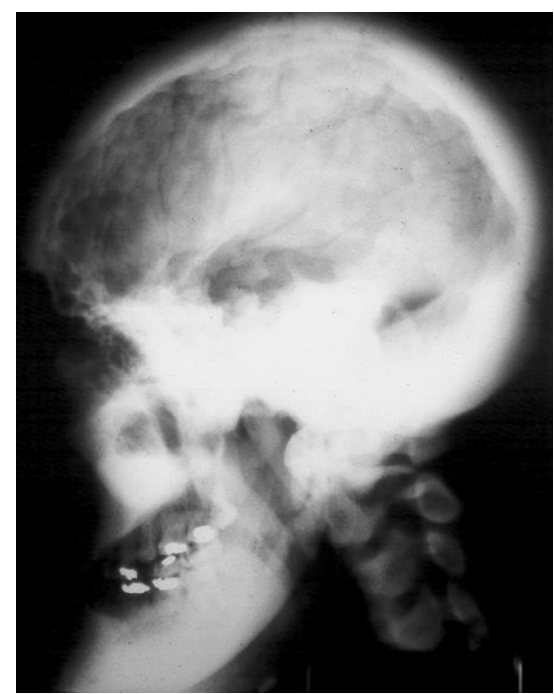

Fig.14: Van Buchem's - Hyperostosis corticalis generalisata - Note the sclerosis of the cranio-mandibular bones.

\section{Camurati -Engelmann disease - Progressive diaphyseal dysplasia}

This is an autosomal dominant disorder which manifests during childhood. The disease begins in the diaphysis of long 
bones. Bilateral and symmetrical cortical findings are noted. It may eventually spread to the metaphysis (fig. 15ab).

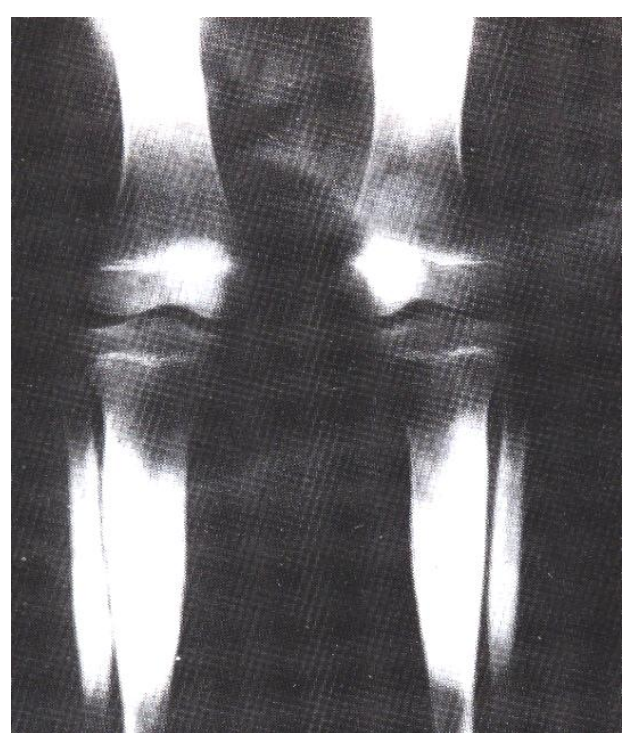

Fig. 15a: Camurati -Engelmann disease Progressive diaphyseal dysplasia involving the bones of the lower limb.

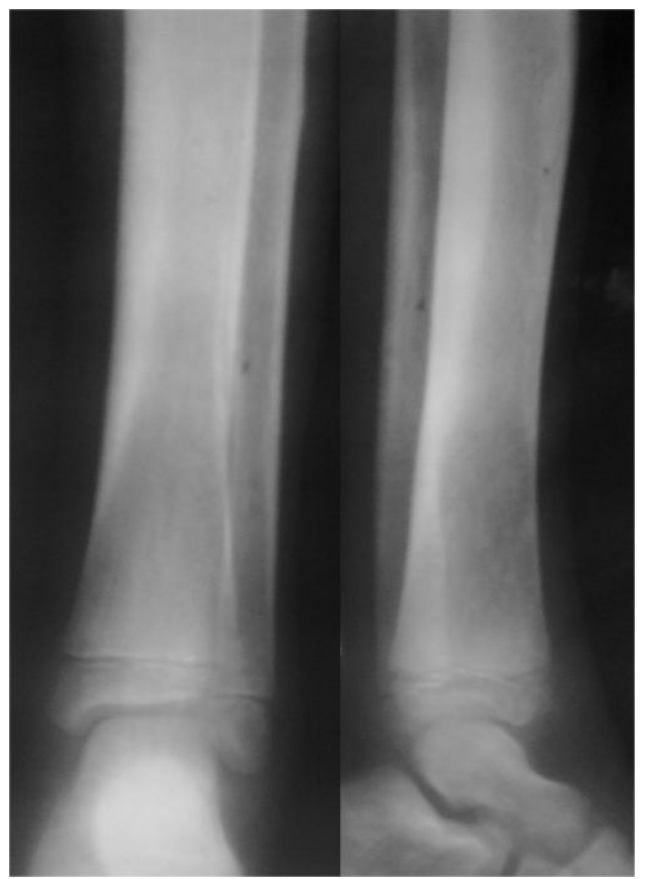

Fig. 15b: Engelmann's disease - Widened diaphyses with new bone indicating progressive diaphyseal dysplasia

The disease is always symmetric and the lower extremities are usually more affected than the upper extremity. In mild cases there is only slight thickening of the cortex in the mid-diaphysis (fig. 16ab). In more advanced cases midshaft scleroses is more pronounced and widespread and involve the diaphysis as well as the metaphysis approaching the epiphysis. Intra articular spaces are not involved. The sclerotic process is accompanied by uniform thickening of cortex. Irregular endosteal and periosteal apposition, and narrowing of the medullary canal. Valgus and Emlenmeyer flask deformities are seen in advanced cases. In severe cases there is sclerosis of the skull base and sometimes mandibular involvement, especially in the region of the temporomandibular joint, in addition to the other findings. In the most severe cases the sclerotic changes involve the entire skull, the vertebral column, metacarpal and metatarsal bones, and the shoulder girdle. The pelvic, carpal, and tarsal bones are not involved.
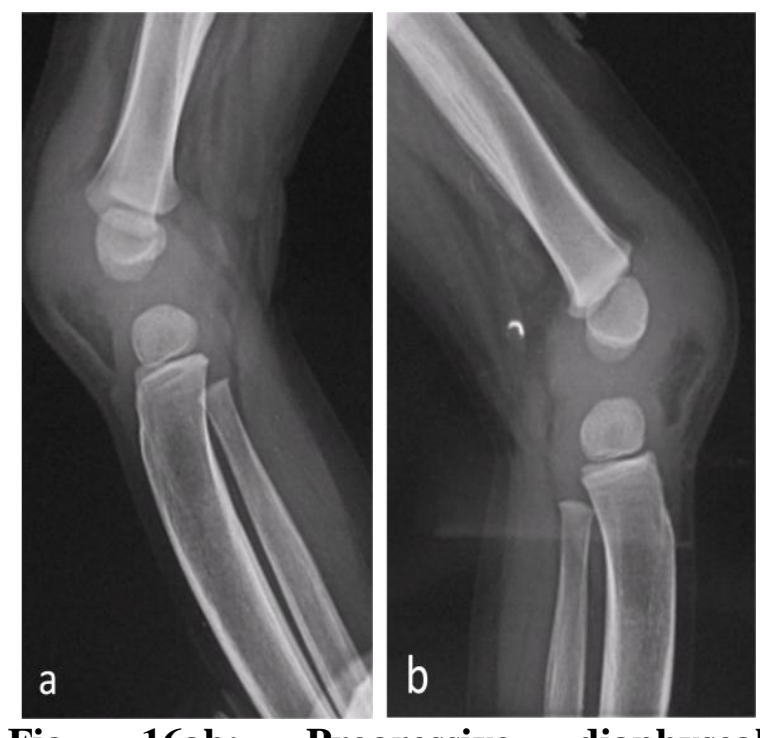

Fig. 16ab: Progressive diaphyseal dysplasia starting at the mid diaphyses of bones of lower extremities.

\section{Ribbing's}

This is hereditary and autosomal dominant recessive. Symetrical, fusiform, diaphyseal, osteosclerosis and hyperosteosis are noted (fig. 17). Single long bone may also be involved.

Differential diagnosis of Ribbings include, progressive diaphyseal dysplasia, (CamuratiEngelmann dysplasia), haemato-diaphyseal dysplasia (Ghosal syndrome) and infantile 
cortical hyperostosis (Caffey's disease) which is not bilateral and symmetrical. Engelmann disease presents during childhood with bilateral and symmetrical bone involvement, whereas ribbing disease may be unilateral and asymmetrical. In Engelmann's the skull is involved whereas in Ribbing's disease only long bones are involved. Engelmann is autosomal dominant while ribbing is autosomal recessive in fact both of them may represent phenotypic variation of the same disorder.

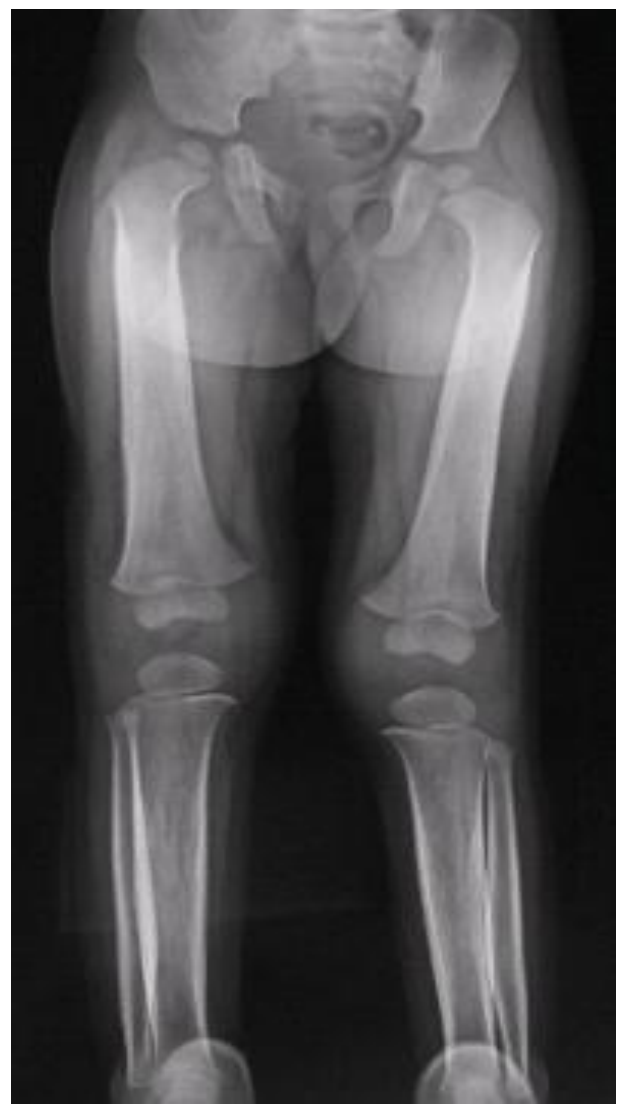

Fig. 17: Ribbing's dysplasia involving the diaphyses

\section{Pyle's Disease - Metaphyseal Dysplasia}

Radiological findings include wide metaphyses with florentine flask deformity of long bones. Wide medial ends of clavicles are also noted (fig. 18ab). In cranium metaphyseal dysplasia, mild hyperostosis of skull is noted, with poor aeration of sinuses and prominent supraorbital ridges (fig. 19).

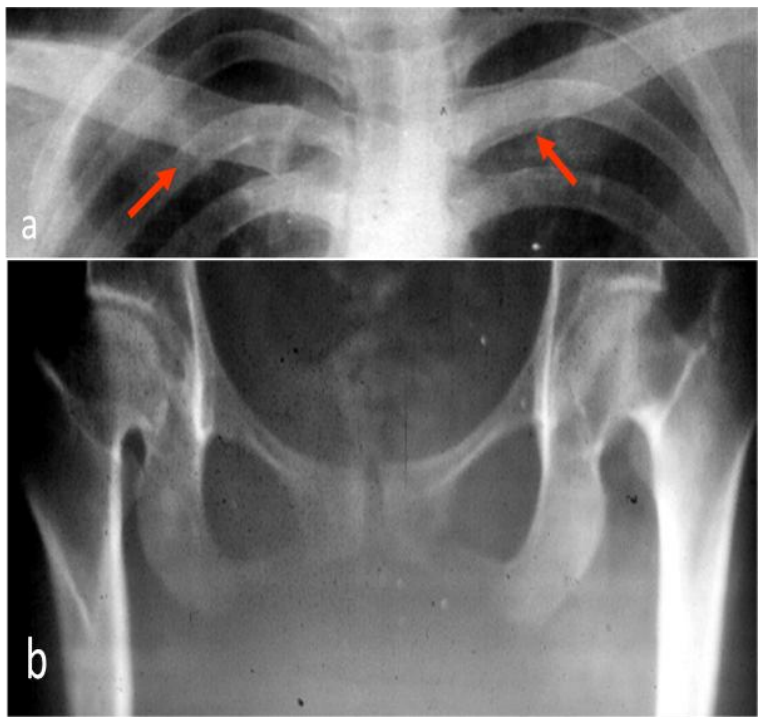

Fig. 18ab: Pyle's - a. flaring of the medial ends of clavicles and proximal ends of femora, b. Note the sclerosis in the pubic bones and coxavara deformity.

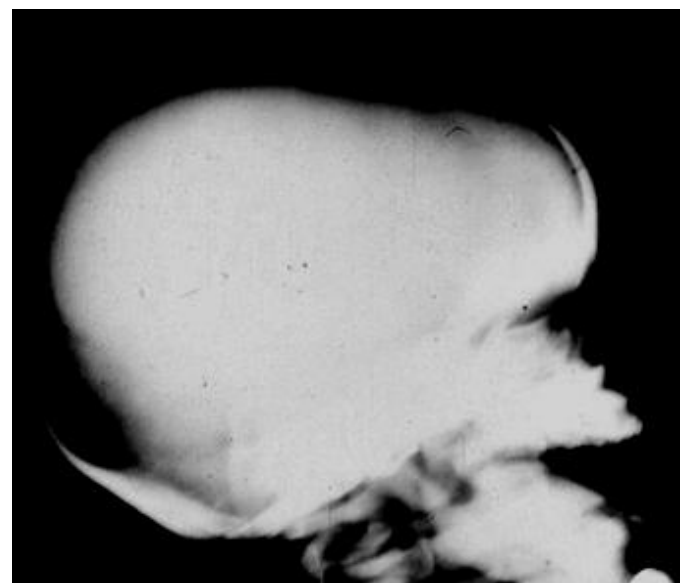

Fig. 19: Cranio Metaphyseal Dysplasia. Note the sclerosis in the base of the skull and mandible.

\section{Melorrheostosis (Flowing Hyperostosis)}

It may be monostotic, monomelic or polyostotic. Radiologically the hyperostosis appears like wax dripping down on one side of the burning candle. Linear and segmental, flowing hyperstosis corresponding to sclerotomes is noted. The hyperostosis skips joints (fig. 20abc). Hyperostotic bone is also noted in soft tissues. The bony over growth simulates osteochondroma (fig. 21). 

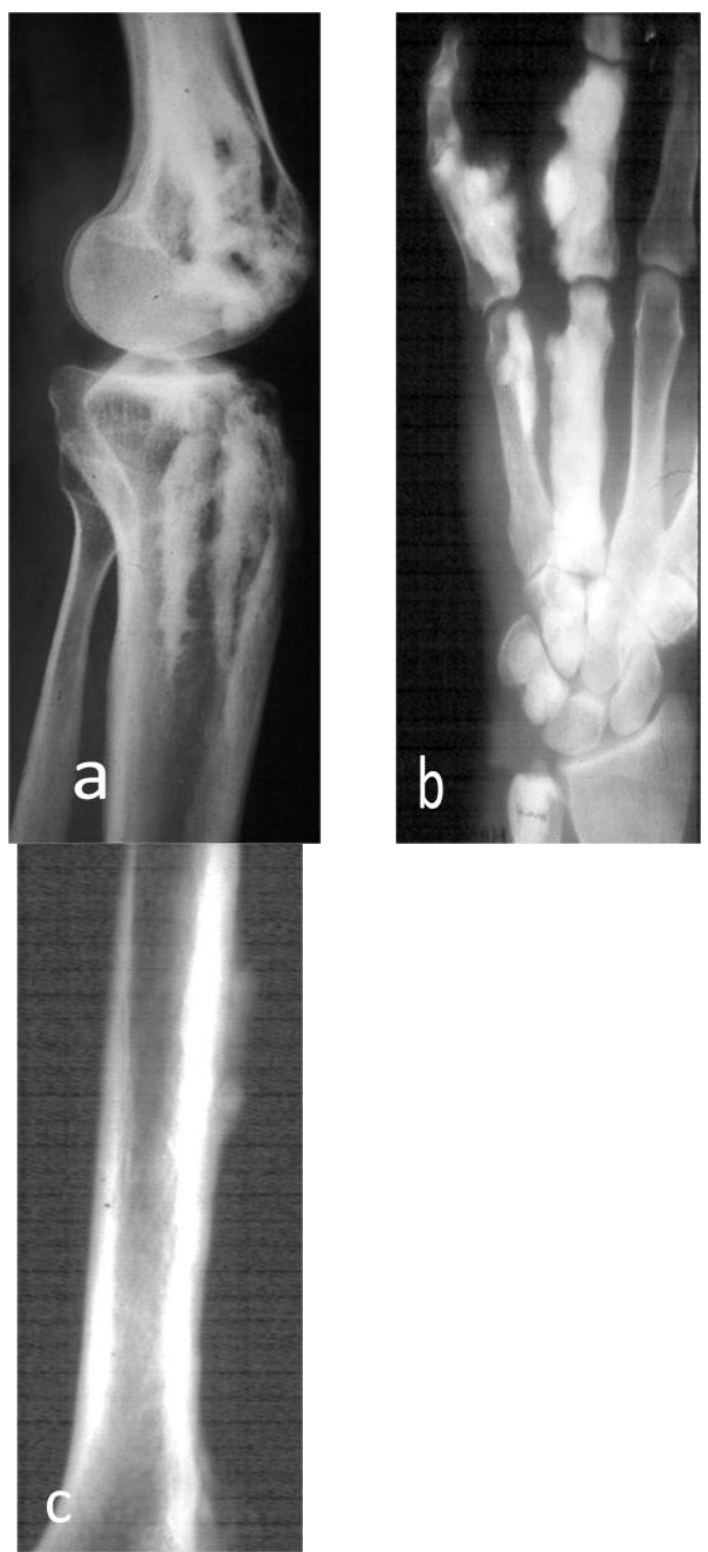

Fig. 20abc: Melorrheostosis - a. Knee, b. Hand c. Femur. Note the hyperosteosis and dripping wax of a burning candle.

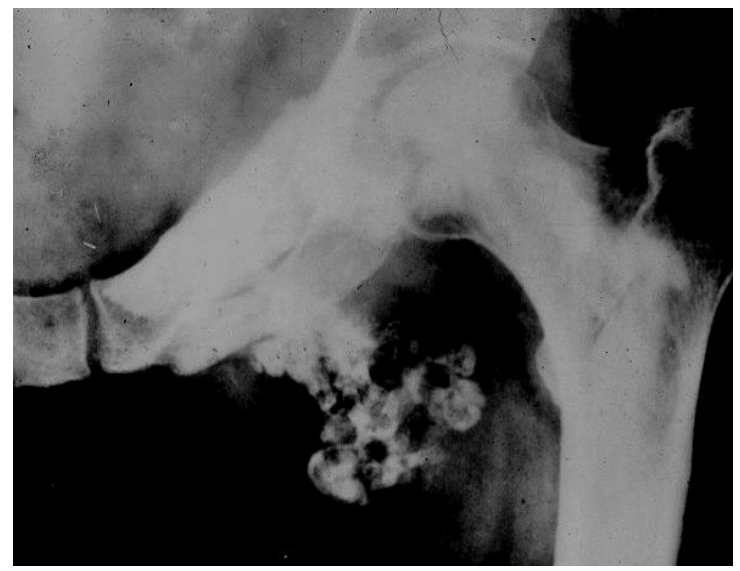

Fig. 21: Melorrheostosis - Simulates exostosis of Ischium.

\section{Familial Hyperphosphatemia \\ (Osteoectasia with Hyperphosphatasia)}

It is a rare disorder and when it occurs in children it is often incorrectly called Juvenile Paget's Disease. This is autosomal recessive and chromosomal studies are normal. Although, the entire skeleton is involved major findings are noted in long bones, spine and skull. Radiologically increase in size of long bones is noted, specifically in transverse diameter. The cortex is thickened and sclerotic with inter sparsed radiolucent zones. The epiphyses are not affected (fig. 22ab). The skull bones are thickened with patchy sclerosis simulating adult Paget's disease. Base of skull and facial bones are normal (fig.23).
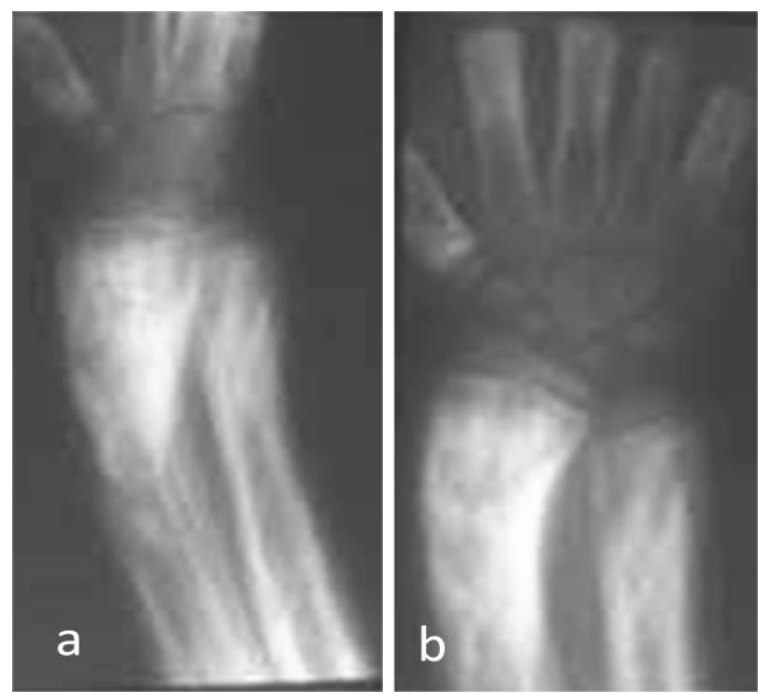

Fig.22ab: Familial Hyperphosphatessemia involving the radius and ulna

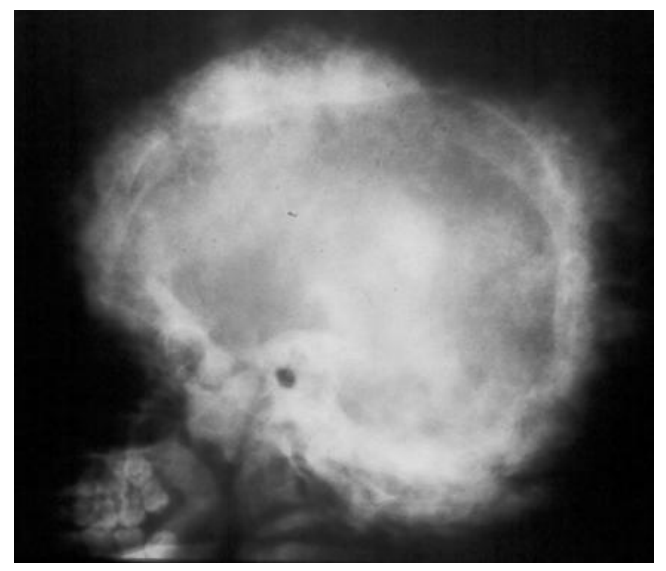

Fig. 23: Hyperphosphatassemia (Juvenile paget's) involving the skull. 
The alkaline phosphatase-1151 (117-390) is elevated as well as serum phosphate. Calcium is normal.

Overlapping Syndromes do occur with coexistence of two or more disorders. Differential diagnoses of acquired entities include osteosclerotic lesions such as Paget, myelofibrosis, metastases, hypoparathyroidism, renal osteodystrophy, sclerosing angiomatosis, fluorosis and tuberous sclerosis.

\section{Pachydermoperiosteosis (Touraine-Solente-Gole Syndrome)}

It generally affects males and clinically simulates acromegaly. It is a familial autosomal dominant disease but can be autosomal recessive or idiopathic. Radiologically excessive non tender periosteal new bone is noted in the bones of the extremities. In long standing cases are periosteum is incorporated into the cortex with loss of normal tubulation (fig.24). Acro-osteolysis may be observed (fig.25). Periosteal over growth may simulate hypertrophic osteopathy. It is also designated as "acromegaloid' osteoarthropathy.Sclerosis of cranium, base and vault of skull is noted.

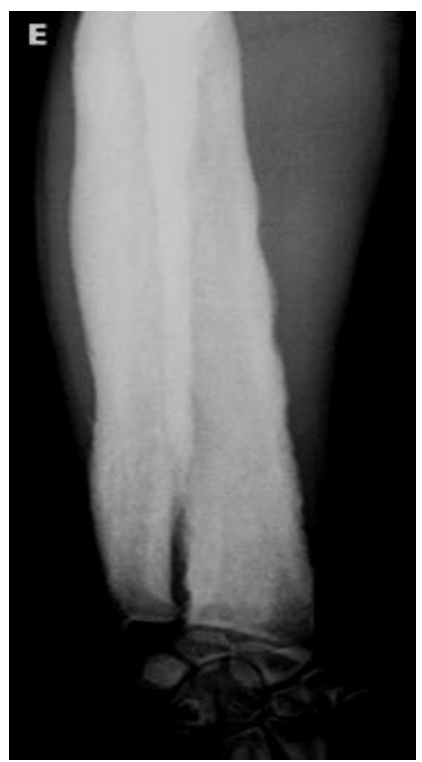

Fig. 24: Pachydermoperiosteosis. Note diffuse cortical thickening and periosteal reaction in the bones of the forearm.

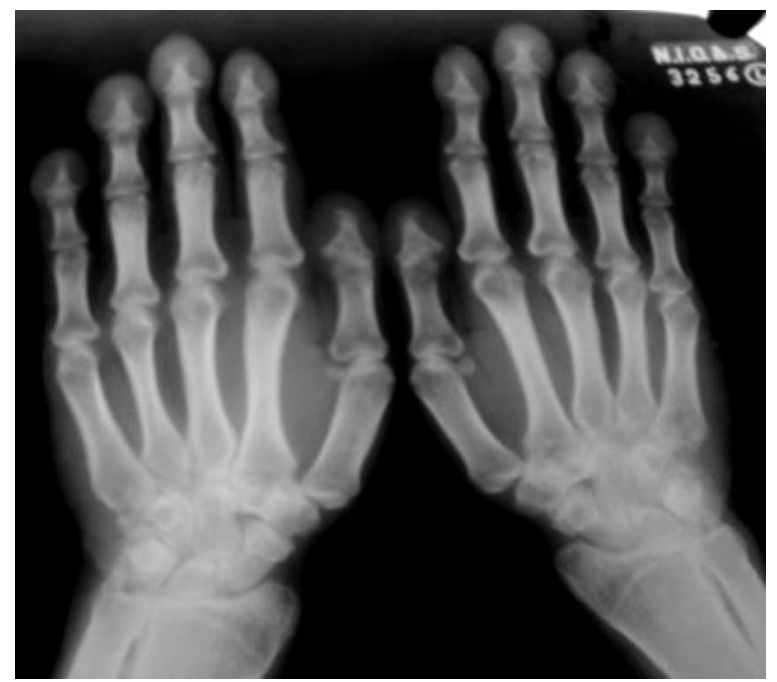

Fig. 24: Pachydermoperiosteosis - Note acroosteolysis and periosteal reaction at the lower ends of bones of forearms.

In all these entities of Sclerosing dysplasia advanced techniques such as ultrasonography, MRI and CT are not necessary. Radionuclide bone scan has been advocated in some disorders such as Camurati Engelmann and Ribbing, to know the extent of involvement of bones.

\section{Conclusion}

Skeletal dysplasias constitute a large variety of congenital disorders. Most of them are genetic and inherited. Genetic studies are crucial. The classification and nomenclature differs with varying authors. Radiologically characteristic findings are noted, although clinical co-relation is necessary. The paper is split into two parts, part one deal with sclerosing dysplasias in which several entities are described with selected radiographic illustrations. Conventional radiology is adequate in most of the cases.

\section{References}

1 Aegerter, E \& Kirkpatrick JA junior, Orthopedic diseases P- 175 to 178; WB Saunders Co. 1968.

2. Amaka C. Offiah and Christine M. Hall, Radiological diagnosis of the constitutional disorders of bone. As 
easy as A,B,C?, Pediatr Radio 2003; $33: 153-161$

3. Beighton P, et al. International Nomenclature of Constitutional Diseases of Bone. Revision, May, 1983. Ann Radiol (Paris) 1983 Sep-Oct;26(6):457-62.

4. Chidambaram NBH, Koramadai KK, Anish H, Baljinder S et al; Tc99m-MDP bone scintigraphy in EngelmannCamurati disease; IJNM;Vol.26:2011.

5. Cremin BJ: Infantile thoracic dystrophy. Br J Radiol,1970;43:199.

6. Cremin BJ, Beighton P: Bone dysplasias of infancy, New York, Springer-Verlag,1978;83-89.

7. Goldberg MJ: The Dysmorphic child. An Orthopedic perspective. New York Raven. Press 1987.

8. Greenspan A. Sclerosing bone dysplasias - a target site approach skeletal radiology (1991)20:561-583.

9. Greenspan A. Sclerosing bone dysplasias: a target site approach. Skeletal RadiolI991;20(8):561-583.

10. Ihde MD, Deborah M et al, Sclerosing Bone Dysplasias: Review and differentiation from other causes of osteosclerosis, Radio Graphics2011; 31: 1865-1882.

11. Kallen et al, Monitoring germ cell Mutations using skeletal dysplasias, Clinical Imaging '93 17 (3)-P:222-234.

12. Kozlowski K, Beighton P. Gamut Index of Skeletal Dysplasias: An Aid to Radiodiagnosis. Berlin: Springer-Verlag, 1984:182-189.

13. Latos-Bielenska A, Marik I, Kuklik M, Matgerna - Kirylum A, Povysil C et al: Pachydermoperiostosis -critical analysis with report of five unusual cases Eur $\mathbf{J}$ Pediatr 2007;166:1237-43.

14. Lenzi-L, Capilupi-B. International nomenclature of constitutional diseases of bone. Intenl. J. Orthop. Frametal. 1985; June 11(2):249-56.

15. Murray RO, Jacobson HG: The radiology of skeletal disorders. 3rd ed. Churchil-Livingstone, Edinburgh 1990.

16. Narang D, Bharati B, Bhattacharya A et al; Radionuclide bone scintigraphy in Engelmann-Camurati disease ; Arch Dis Child 2004;89:737.

17. Naveh Y, Kaftori JK, Alon D, BenDavid J, Berant M. Progressive diaphyseal dysplasia: genetics and clinical and radiologic manifestations. Pediatrics 1984;74(3):399-405.

18. Neuhauser EB, Shwachman H, Wittenborg $\mathrm{M}$, et al. Progressive diaphyseal dysplasia. Radiology 1948; 51(1):11-22.

19. Ribbing S. Hereditary, multiple, diaphyseal sclerosis. Acta Radiol 1949;31 (5-6):522-536.

20. Seeger LL, Hewel KC,Yao L, et al. Ribbing disease (multiple diaphyseal sclerosis): imaging and differential diagnosis. AJR Am J Roentgenol 1996; 167(3):689-694.

21. Spranger JW, langer LO, Wiedeman HR: Bone dysplasias. An Atlas of constitutional disorders of skeletal development. Philadelphia, WB Saunders 254:68-85,1974.

22. Taybi H, Lachman RS. Radiology of syndromes, metabolic disorders, and skeletal dysplasias. (4th ed.) Chicago: Year Book, 1996. 